Article

\title{
Localization Free Energy Efficient and Cooperative Routing Protocols for Underwater Wireless Sensor Networks
}

\author{
Sahar Shah ${ }^{1}$, Anwar Khan 1,2,*(D), Ihsan Ali ${ }^{3} \mathbb{D}$, Kwang-Man Ko ${ }^{4, *}$ and Hasan Mahmood ${ }^{1}$ \\ 1 Department of Electronics, Quaid-i-Azam University, Islamabad 45320, Pakistan; \\ saharshah@ele.qau.edu.pk (S.S.); hasan@qau.edu.pk (H.M.) \\ 2 Department of Electronics, University of Peshawar, Peshawar KPK 25120, Pakistan \\ 3 Department of Computer System and Technology, Faculty of Computer Science and Information Technology, \\ University of Malaya, Kualalumpur 50603, Malaysia; ihsanalichd@siswa.um.edu.my \\ 4 Department of Computer Science and Engineering, Sangji University, Wonju-si 220-702, Korea \\ * Correspondence: arkhan@uop.edu.pk (A.K.); kkman@sangji.ac.kr (K.-M.K.); Tel.: +92-300-583-8914 (A.K.)
}

Received: 27 September 2018; Accepted: 10 October 2018; Published: 15 October 2018

\begin{abstract}
Mitigation of channel unfavorable circumstances during data routing in underwater wireless sensor networks (UWSNs) has utmost significance. It guarantees saving packet corruption along unfavorable channels so that vital data is not lost or become meaningless. This paper proposes two routing protocols for UWSNs: localization free energy efficient routing (LFEER) and its improved version, localization free energy efficient cooperative routing (Co-LFEER). The LFEER makes decision of choosing a relay based on its maximum residual energy, number of hops and the bit error rate of the link over which packets are transmitted. These metrics are chosen to save packets from corruption to the maximum limit and maintain stable paths (where nodes do not die soon). Since a single link is used in the LFEER for packets forwarding, the link may become worse with changing circumstances of the channel. To deal with this issue, cooperative routing is added to the LFFER to construct the Co-LFEER protocol, in which some copies of packets are received by destination to decide about packets quality. Converse to some prevalent protocols, both LFEER and Co-LFEER are independent of knowing the sensor nodes' positions, which increases computational complexity and wasteful utilization of resources. Based on extensive simulations, the proposed schemes are better than Co-DBR in reducing energy utilization and advancing packets to the desired destination.
\end{abstract}

Keywords: UWSNs; LFEER; Co-LFEER; routing

\section{Introduction}

Maintaining the energy efficiency with the reliability of the network in UWSNs is challenging. The nodes in UWSNs consume energy to communicate with one another. The limited energy is supplied to each node in UWSNs. The cost of the network increases by deploying the entire network again when the energy of the nodes is consumed [1]. By increasing the lifetime of the networks, more information forwarding can be achieved. Many protocols in the literature minimize the consumption of energy in UWSNs [2,3]. The reliability of the UWSNs decreases when the packet delivery ratio (PDR) spoils and this happens due to channel properties [4,5]. The maximum reliability of the networks can be achieved by designing protocols that address the unwanted channel parameters. By following this, maximum information reaches the desired target. The practical accomplishment of the energy efficient and reliable protocols is needed in situations such as underwater forecasting, pathfinding for underwater vehicles, oil leakage and spying [6].

UWSNs are well known to assemble the messages from the nodes and forward them in the direction of the final destination node (DNN). However, in sending information packets from 
underneath to top of the water surface, many challenges are faced such as multi-path fading, propagation delay and high bit error rate, among many others [7]. By facing these challenges, reliability and energy of the networks are affected. Thus, for the sake of improving networks reliability, many cooperative routing protocols have been designed [8,9]. However, these protocols have not been energy efficient and thus have high energy consumption of the networks. The limited power is supplied to underwater networks and it requires much effort to change or recharge the battery [10]. Therefore, plenty of energy efficient protocols without cooperation are proposed to minimize the energy usage, but the PDR is reduced [11].

The destination (DSN) and relay nodes (RLNs) work together to transmit the information bags to the sink nodes in cooperative routing. Cooperative communication has two schemes: the first one is the fixed relaying scheme and the second is the adaptive relaying scheme [12]. Fixed relaying scheme has further two sub-schemes, i.e., fixed amplify-and-forward (AF) relaying and fixed decode-and-forward (DF) relaying. In AF relaying, the forwarder node receives the information packet and amplifies it and then transmits to the DSN. In DF, the forwarder node decodes the information, re-encodes it and transmits in the direction of the DSN [13].

Many cooperative and localization based protocols are designed for UWSNs [14-16]. These protocols need full localization information of each node. To get the localization information of each node, GPS or some measure of the received signal power is required, and, as a result, the cost of the networks increases [17].

In this paper, two routing protocols for UWSNs are proposed. The first proposed protocol is called localization free energy efficient routing (LFEER). The proposed protocol has an energy efficient mechanism which consumes minimum energy in data bags forwarding. The LFEER protocol defines the DSN selection criteria. The selection criteria for the DSN are set through a function. The function has three parameters. These parameters are: residual energy, number of hops and bit error rate (BER). The source nodes broadcast the information bags. The node which has the highest residual energy, the fewest hops and the lowest BER over the transmitting link is chosen as the DSN. If a mechanism for the selection of DSN is not considered, then all nodes which are in source nodes transmission range forward the information packets towards the final DNN. Hence the tremendous energy is consumed by all nodes, as a result the network is probable to die quickly.

The second proposed protocol is called localization free energy efficient cooperative routing (Co-LFEER). It is the improved version of the LFEER protocol. The selection criteria for the DSN in LFEER and Co-LFEER is the same. The same parameters (residual energy, number of hops, BER) are used to choose RLNs. However, in Co-LFEER, cooperation between the DSN and RLN is considered. Unlike many other cooperative routing protocols $[8,18]$, Co-LFEER selects only one RLN and DSN to transmit data bag towards the final DNN. By choosing a single forwarder node and the DSN, the consumption of the energy is controlled. The number of hops and BER for the selection of DSN and RLNs minimize the path loss effects on the data packets, thus the maximum information bags are transmitted to the final DNN. The highest value of the function (residual energy, number of hops, BER) is assigned to the DSN and the second highest value is assigned to the RLN.

This paper contributes in the following ways:

- LFEER: In the proposed localization free energy efficient routing protocol, the DSN is chosen based on residual energy, number of hops and bit error rate values. The source node chooses only one DSN from the neighbor nodes. That node is chosen as a DSN which has the maximum residual energy, fewest hops and minimum bit error rate. Due to these parameters and mechanism, the energy consumption of the nodes is controlled, which increases the battery lifetime.

- Co-LFEER: The improved version of the proposed LFEER is called localization free energy efficient cooperative routing. Here, one RLN is considered. The DSN and the RLN are chosen on the parameters: residual energy, number of hops and BER. The DSN is chosen among the many existing nodes in the field of the source node. The node which has the maximum residual energy, fewest hops and least BER is chosen as a DSN to transmit the information bags. The RLN selection 
parameters are the same as for the DSN. The RLN is selected based on second maximum/least values of the same parameters as for the DSN. The fewest hops and minimum BER parameters control the channel effects on the information bags and, as a result, PDR is improved.

- No Localization: The proposed protocols are localization free and do not need the exact location of the nodes which reduces the cost of the network.

\section{Related Work}

This section discusses related algorithms for UWSNs.

A cooperative algorithm is proposed in [19]. The network is divided into four regions. The list is prepared for all neighbor nodes in descending order and the protocol sorts and selects the destinations (DSNs) on the parameter values: higher residual energy and lowest depth. The source node forwards the information bag in the direction of the destination and forwarder node present in the same region. The protocol has a good lifetime of the network and maximizes the packet acceptance ratio. However, due to cooperation in the data packets forwarding, it maximizes the delay of the network. The nodes near to the sink die quickly because of high data traffic.

The authors propose three energy efficient protocols in [20]. In the first protocol, the DSNs are chosen on the lowest depth and residual energy. The network lifetime increases in this protocol. In the second protocol, the DSNs are chosen on the fewest hops and lowest depth. This protocol decreases the path loss effects in data packet transmission. In the third protocol, the destination nodes are chosen on depth, residual energy, and the fewest hops. It improves the battery lifetime and packets delivery ratio. However, the destination node selection criteria increases the delay. The lowest depth nodes are mostly used and thus die quickly.

In [21], the source nodes need information about depth and residual energy of relays for data transmission. The optimal forwarder is chosen from the set of forwarder nodes through the fuzzy logic mechanism. The relay nodes having the maximum PDR are chosen to transmit the information packets in the direction of destination nodes. The forwarder node waits for the defined interval of time before forwarding the data bags. The protocol has good results in energy and delay as well as because of cooperation high PDR is achieved. On the other hand, there is no checking mechanism either the data packets received are correct or erroneous.

In [22], two partner forwarder nodes and the destination node transmit the information packets. The selection criteria of the destination and forwarder nodes are classified in two ways. The nodes are chosen on depth, residual energy and quality of the channel as well as on the signal-to-noise ratio (SNR). This algorithm improves the packet acceptance ratio. On the other hand, the protocol is not good in terms of delay.

In [23], a proposed protocol considers the three parameters residual energy, depth and the link quality for choosing destination nodes. The link quality of the source nodes with the destination and forwarder nodes is considered. Depth threshold $\left(D_{t h}\right)$ is defined and varied according to alive nodes. Within the $\left(D_{t h}\right)$, the relay nodes are selected while the destination nodes are chosen its outside. If source nodes have no neighbor nodes in their range of $\left(D_{t h}\right)$, then the information packets are transmitted towards the destination nodes directly. If the source nodes have no neighbor nodes outside the $\left(D_{t h}\right)$, then the forwarder nodes are chosen as the destination nodes. If source nodes have no neighbor nodes inside and outside the $\left(D_{t h}\right)$, then data packets are dropped. Due to cooperation, the destination nodes receive two copies of information packets which are then combined by MRC technique. The protocol has good throughput. On the other hand, the protocol has maximum energy usage.

Region-based cooperative protocol is presented in [16], in which the choice of destination and forwarder nodes depends on three parameters: depth, residual energy and SNR. To determine the location of the nodes, instead of GPS, the protocol uses received signal strength indicator (RSSI) with Mote-track technique. Based on the above mechanism, neighbor nodes are identified and selected. Four mobile final destination nodes are selected to receive the information bags from sensor nodes 
in half-duplex mode. Cooperation is performed when the destination nodes receive the data packets with BER value greater than 0.5. Then, it requests to forwarder nodes to transmit their data packets to destination nodes. The MRC technique is applied at the destination nodes. It improves the PDR and decreases the errors probability. However, the techniques used in this protocol increase the energy consumption.

In [24], a protocol is proposed, in which the network is split into three zones and nodes spread with different depth and positions. The nodes deployed in the upper zone have depth from $0 \mathrm{~m}$ to $300 \mathrm{~m}$ and can transmit the information packets to final destination node directly. The nodes present in the middle zone have the depth from $300 \mathrm{~m}$ to $700 \mathrm{~m}$ and these nodes work as the relay nodes for lower zone nodes. The optimal relay nodes have depth range from $400 \mathrm{~m}$ to $600 \mathrm{~m}$. The nodes selected in this specified depth region are called optimal relay nodes for lower zone nodes. The middle zone nodes can directly communicate with the final destination node or through relay nodes. The lower zone nodes have the depth of $700 \mathrm{~m}$ to $1000 \mathrm{~m}$. If no relay nodes found in the transmission area of the source nodes, then it communicates straight with the sink node with maximum energy consumption. The protocol highly improves the total energy consumption. However, by choosing only one sink node, delay of the network increases.

The protocol presented in [5] extends the work of [24] by adding cooperation between the destination and forwarder nodes. The lowest depth and lowest distance values are considered to choose the destination nodes. The distance values of the nodes can be found by the current distance of the nodes from the final node. The nearest nodes to the destination are considered as the optimal relay nodes. In this way, two data packet copies are merged via MRC and checked for BER. The BER threshold is fixed at 0.5 . If the BER value of the received information bags at the destination node is greater than the BER threshold value, then it requests to the forwarder node for sending its own data packet. If BER satisfies the threshold value, then destination node accepts and forwards the information packet towards the sink node. If no relay nodes are available in the source nodes range, then only destination nodes forward the information packets in the direction of sink node. This protocol increases the packets delivery ratio and decreases the total packet drop. On the other hand, by selecting only one sink node and due to cooperation in data packets forwarding, delay increases.

In (DEADS) [25], Amara Umar et.al propose cooperation based protocol. The nodes are deployed in a random manner where one-hop neighbor nodes know the depth and residual energy of the neighbor nodes. The network periodically updates the depth information. The network has four different regions in which nodes are deployed. If there are more alive nodes, the depth threshold value is greater and vice versa. The depth information is needed for one neighbor hop instead of the whole network, thus data flooding is eliminated. The nodes having the lowest depth and maximum residual energy values are used as forwarders. The destination nodes can select single or multiple relay nodes from its neighbor nodes. If there are no neighbor nodes to source nodes, then the source nodes perform no function and go to sleep mode. If final destination nodes are in the field of source nodes, then source nodes directly transmit the information packets to the final destination nodes. While performing cooperation by the nodes, the destination nodes receive two copies of data packets which are combined by MRC and directed towards the next destination or sink nodes. The nodes follow linear or elliptical motion. This protocol out-performs some existing protocols in alive nodes, dead nodes, residual energy and PDR. However, packets drop increases because of not optimizing the elliptical mobility pattern.

The energy issue is not only related with the UWSNs but also it is important in terrestrial networks. In [26], the authors propose an algorithm to minimize the energy consumption between the two devices when they want to communicate. The coalition method is adopted rather than clustering. Moreover, it also investigates the quality of the channel. The framework is divided into two key steps. Firstly, the devices mainly focus on energy and the quality of the channel along with the interest interaction between them. The main function has been performed by the head of coalition. Secondly, the proposed 
algorithm focuses on the quality of the service when the two machines want to communicate with each other. Overall, the performance of the proposed work is good at reducing energy usage.

The authors in [27] device an optimized clustering mechanism that has no fixed body and is randomly adopted. The approach tackles the existing challenges including time synchronization problem. In addition, it enables to communicate a mobile even when the base station goes dead by using the process of multi-hop. A node can find its corresponding cluster even in the scenario of mobility. The approach enhances the quality by not mixing the codes of many users. Rather, it uses only one code for only one cluster. The algorithm outperforms in terms of throughput, delay and packet loss. However, the bandwidth is narrow.

A new approach is presented in [28] to enhance the basic functions in Internet of Things (IoT). The authors used the wireless system of the power approach to communicate between two machine devices. To make clusters between two machine devices, the cluster making algorithm is used. The IoT basic parameters are used to create interaction interest between the two machines. Energy adaptation mechanism from the clusters head uses radio signals. The simplest policies are used to create the clusters to reduce the complication. The utility function plays a key role through which head of a cluster varies its energy according to operation. A game theoretic approach has been applied on two machines that want to communicate in a non-cooperative manner in terms of transmission power. These functions make the proposed work independent in terms of properties, management, and adaptation, which helps the devices to work in optimal response. The paper has outstanding results in increasing the energy of the system. The techniques used make the machines independent. However, the battery is fixed and has limited energy.

In [29], the authors show the ways clusters are made in wireless system to manage energy factor for a system. Unlike active clustering, passive clustering is free from the instantaneous beacon signal, which is the main reason it saves energy. Nodes' mobility is not considered, which affects link quality and is the main point of maximum energy usage. The scheme has the ability to enhance its characteristics when its demand is at the peak point. There is no surety that a node has all information of the nearby nodes. To have all the information of nearby nodes, a uniform radio-transmitted power is used. The scheme is easy to implement and is mostly used when the goal is cluster making. The overall performance of the standby algorithm is good for achieving maximum throughput. However, the standby approach requires four states by using two bits to achieve all the necessary data of nearby nodes.

Quick response and immediate transmission of data with efficient mechanism regarding energy are not only limited to UWSNs but are also the requirement of wireless land systems. In [30], the authors use an advance multiplexing technique when two devices want to communicate with each other in a public network. The two parameters responsible for the two devices to conserve energy are social and physical behaviors. The movement of the users is noticed when the users are in energy saving mode. Inside the field of transmission, the users, by using a reference point, can find other users having the same pattern of movements. This type of communication saves the extra usage of energy. However, using such deployment of the frame is risky and can be destroyed by earthquake and flooding.

In [31], authors show that the throughput enhancement is not only necessary in UWSNs but also in terrestrial systems. The scheme works for many-media traffic using multiplexing in time and code. This framework does not involve any wired connection. Many nodes combine to form a cluster by using an algorithm called distributed clustering algorithm. The heads of all clusters operate as instructors and decision makers, making the decisions for data routing using channel alignment and power requirement. The framework eases time management for every node and improves the setting of codes and time. The setting of bandwidth use varies according to performance and actions. The standby algorithm performs well for maximizing the throughput and reducing the disconnections. However, this protocol is only applicable to wireless networks and has no arrangement for the wired backup, as is usually done.

Tables 1 and 2 summarize the key findings of the protocols described in the Related Work Section. 
Table 1. Related Work Summary.

\begin{tabular}{|c|c|c|c|c|}
\hline Protocol & Features & Advantages & Shortcomings & Reference \\
\hline EACE & $\begin{array}{l}\text { The protocol involves energy } \\
\text { efficient and cooperative } \\
\text { mechanisms. The best } \\
\text { destination nodes are selected } \\
\text { based on maximum residual } \\
\text { energy and lowest depth. }\end{array}$ & $\begin{array}{l}\text { The network lifetime } \\
\text { is good and has } \\
\text { maximum packet } \\
\text { acceptance ratio. }\end{array}$ & $\begin{array}{l}\text { As a result of } \\
\text { cooperation, delay } \\
\text { of the network } \\
\text { increases and the } \\
\text { nodes nearer the } \\
\text { final destination } \\
\text { nodes have higher } \\
\text { death ratio. }\end{array}$ & [19] \\
\hline IAIEEDBR & $\begin{array}{l}\text { The protocol selects the } \\
\text { destination nodes based on } \\
\text { depth, residual energy and } \\
\text { number of hops. }\end{array}$ & $\begin{array}{l}\text { Energy consumption } \\
\text { is economical, } \\
\text { network lifetime } \\
\text { is improved and } \\
\text { interference is } \\
\text { reduced. }\end{array}$ & $\begin{array}{l}\text { Network delay } \\
\text { increases. Nodes } \\
\text { closer to the final } \\
\text { destination are used } \\
\text { most often and thus } \\
\text { die more quickly. }\end{array}$ & [20] \\
\hline EECOR & $\begin{array}{l}\text { In this protocol, from the relay } \\
\text { set, the best relay node is } \\
\text { selected using Fuzzy logic. The } \\
\text { destination nodes are chosen } \\
\text { using depth and residual energy } \\
\text { information. }\end{array}$ & $\begin{array}{l}\text { It consumes less } \\
\text { energy, minimizes the } \\
\text { delay and increases } \\
\text { the PDR. }\end{array}$ & $\begin{array}{l}\text { There is no } \\
\text { mechanism for } \\
\text { checking if data } \\
\text { packets are correct } \\
\text { or erroneous. }\end{array}$ & [21] \\
\hline Coop & $\begin{array}{l}\text { This algorithm is cooperation } \\
\text { based. The depth and residual } \\
\text { energy values are used to select } \\
\text { the destination and relay nodes } \\
\text { with their link with the source } \\
\text { nodes and SNR. }\end{array}$ & $\begin{array}{l}\text { This protocol is good } \\
\text { in term of packet } \\
\text { acceptance ratio. }\end{array}$ & $\begin{array}{l}\text { The protocol is } \\
\text { cooperation based, } \\
\text { thus the delay } \\
\text { increases. }\end{array}$ & [22] \\
\hline DEAC & $\begin{array}{l}\text { Choosing the destination nodes } \\
\text { requires information on three } \\
\text { parameters: energy that resides } \\
\text { in a node's battery, depth and } \\
\text { link quality. Depth threshold } \\
\text { (Dth) focuses on alive nodes and } \\
\text { varies according to it. }\end{array}$ & $\begin{array}{l}\text { The packet } \\
\text { acceptance ratio } \\
\text { increases at the final } \\
\text { destination. }\end{array}$ & $\begin{array}{l}\text { It has high energy } \\
\text { consumption. }\end{array}$ & [23] \\
\hline RBCRP & $\begin{array}{l}\text { In this localization based } \\
\text { protocol, the selection criteria of } \\
\text { destination and relay nodes are } \\
\text { depth, residual energy and SNR } \\
\text { values. The RSSI is used to find } \\
\text { the location of the nodes. }\end{array}$ & $\begin{array}{l}\text { Packets dropped } \\
\text { decreases, as does the } \\
\text { error probability. }\end{array}$ & $\begin{array}{l}\text { It increases the } \\
\text { consummation } \\
\text { of energy. }\end{array}$ & [16] \\
\hline EEORS & $\begin{array}{l}\text { The protocol is energy efficient } \\
\text { and the optimal relay nodes have } \\
\text { the depth zone from } 400 \text { to } 600 \mathrm{~m} \text {. } \\
\text { The nodes in this range are relay } \\
\text { nodes for lower zone nodes. }\end{array}$ & $\begin{array}{l}\text { Economical } \\
\text { utilization of energy. }\end{array}$ & $\begin{array}{l}\text { A single sink } \\
\text { increases } \\
\text { network delay. }\end{array}$ & [24] \\
\hline
\end{tabular}


Table 2. Related Work Summary.

\begin{tabular}{|c|c|c|c|c|}
\hline Protocol & Features & Advantages & Shortcomings & Reference \\
\hline CO-EEORS & $\begin{array}{l}\text { The best destination nodes are } \\
\text { selected in this protocol based } \\
\text { on lowest depth and distance } \\
\text { values. If no relay nodes are } \\
\text { found in neighborhood, then only } \\
\text { destination nodes are selected. The } \\
\text { MRC technique is used at the } \\
\text { destination nodes. }\end{array}$ & $\begin{array}{l}\text { It increases the } \\
\text { packets delivery } \\
\text { ratio and decreases } \\
\text { the packets drop. }\end{array}$ & $\begin{array}{l}\text { It increases } \\
\text { the energy } \\
\text { consumption } \\
\text { and delay. }\end{array}$ & [5] \\
\hline DEADS & $\begin{array}{l}\text { In this protocol, the network is } \\
\text { divided into four zones based on } \\
\text { depth. Depth threshold mechanism } \\
\text { avoids data flooding. Power } \\
\text { residing in a node's battery and } \\
\text { its depth decide its selection as } \\
\text { a relay or as a destination. The } \\
\text { nodes can move in the elliptical and } \\
\text { linear direction. }\end{array}$ & $\begin{array}{l}\text { It improves the } \\
\text { network lifetime } \\
\text { and packets delivery } \\
\text { ratio. }\end{array}$ & $\begin{array}{l}\text { The protocol } \\
\text { fails in elliptical } \\
\text { mobility pattern } \\
\text { optimization, } \\
\text { which increases } \\
\text { packets drop. }\end{array}$ & [25] \\
\hline $\begin{array}{l}\mathrm{i}-\mathrm{q}, \mathrm{q}, \mathrm{i} \\
\text { approach }\end{array}$ & $\begin{array}{l}\text { The coalition, physical awareness, } \\
\text { link quality, and energy efficiency } \\
\text { are the main goals of the proposed } \\
\text { work. The energy usage of } \\
\text { the devices is reduced when IOT } \\
\text { devices communicate with each } \\
\text { other, through the above factors. }\end{array}$ & $\begin{array}{l}\text { The proposed work } \\
\text { is best to increase } \\
\text { the life of the } \\
\text { framework. }\end{array}$ & $\begin{array}{l}\text { How to achieve } \\
\text { maximum PDR is } \\
\text { not discussed. }\end{array}$ & [26] \\
\hline ACMWN & $\begin{array}{l}\text { The algorithm defines a new } \\
\text { clustering technique with good } \\
\text { quality. The main task of the } \\
\text { approach is to avail the techniques } \\
\text { with maximum throughput and } \\
\text { less delay. Selecting only one } \\
\text { cluster eliminates the interference }\end{array}$ & $\begin{array}{l}\text { The main } \\
\text { achievement of } \\
\text { the algorithm is to } \\
\text { reduce the drop of } \\
\text { packets, enhancing } \\
\text { the transmission. }\end{array}$ & $\begin{array}{l}\text { The framework } \\
\text { has limited } \\
\text { bandwidth. }\end{array}$ & [27] \\
\hline $\mathrm{I}, \mathrm{IP}, \mathrm{P}$ & $\begin{array}{l}\text { The standby algorithm design } \\
\text { is independent in properties, } \\
\text { management and adaptation. The } \\
\text { self energy adaptation mechanism } \\
\text { is introduced. By using utility } \\
\text { function, energy consumption will } \\
\text { vary with the cluster head. }\end{array}$ & $\begin{array}{l}\text { The goal is to } \\
\text { enhance the energy } \\
\text { and independence } \\
\text { of the cluster. }\end{array}$ & $\begin{array}{l}\text { The battery is } \\
\text { fixed and not } \\
\text { rechargeable. }\end{array}$ & [28] \\
\hline $\mathrm{AODV} / \mathrm{PC}$ & $\begin{array}{l}\text { The scheme considers no mobility } \\
\text { which avoids the complexity in } \\
\text { getting nearby information and } \\
\text { link measurement. Many clusters } \\
\text { can be made more easily than the } \\
\text { traditional mechanisms. }\end{array}$ & $\begin{array}{l}\text { It avoids the high } \\
\text { traffic on clusters. }\end{array}$ & $\begin{array}{l}\text { The scheme } \\
\text { follows a } \\
\text { challenging } \\
\text { mechanism to } \\
\text { collect nearby } \\
\text { nodes data. }\end{array}$ & [29] \\
\hline S-PMAC & $\begin{array}{l}\text { This framework uses advanced } \\
\text { multiplexing wireless technique to } \\
\text { deliver data between two devices. } \\
\text { The physical and social behaviors of } \\
\text { the users are used in connecting two } \\
\text { devices. Similar nearby users with } \\
\text { the same mobility can be found in a } \\
\text { user field through a reference point. }\end{array}$ & $\begin{array}{l}\text { This approach helps } \\
\text { connect two users } \\
\text { using less energy. }\end{array}$ & $\begin{array}{l}\text { The framework } \\
\text { can be damaged } \\
\text { through disaster } \\
\text { occurrence. }\end{array}$ & [30] \\
\hline
\end{tabular}


Table 2. Cont.

\begin{tabular}{llllll}
\hline Protocol & Features & Advantages & Shortcomings & Reference \\
\hline MCMMRNs & $\begin{array}{l}\text { The multiplexing in time and code } \\
\text { is used to deal with many-media } \\
\text { services. The distributing method }\end{array}$ & $\begin{array}{l}\text { theduces } \\
\text { connectivity }\end{array}$ & $\begin{array}{l}\text { No backup wire } \\
\text { arrangement }\end{array}$ & [31] \\
is used for clustering. The head & & & \\
& $\begin{array}{l}\text { of clusters are responsible for } \\
\text { managing and making available the } \\
\text { channel, power, time and its reuse } \\
\text { according to conditions. }\end{array}$ & & \\
\end{tabular}

\section{Proposed Algorithms Explanation}

In this section, the proposed protocols: LFEER and Co-LFEER, are explained thoroughly.

\subsection{Localization Free Energy Efficient Routing Protocol (LFEER)}

\subsubsection{Network Architecture}

Figure 1 sketches the network as a cube of depth $500 \mathrm{~m}$. The nodes deployment is irregularly spaced and initially a node possesses a specific amount of energy. The forwarding range of each node is defined. Four final DNNs are considered and situated at the upper area of the network. The nodes communicate via acoustic waves with each other as well as with the final DNN. The final DNNs communicate through radio waves with each other and with satellite station.

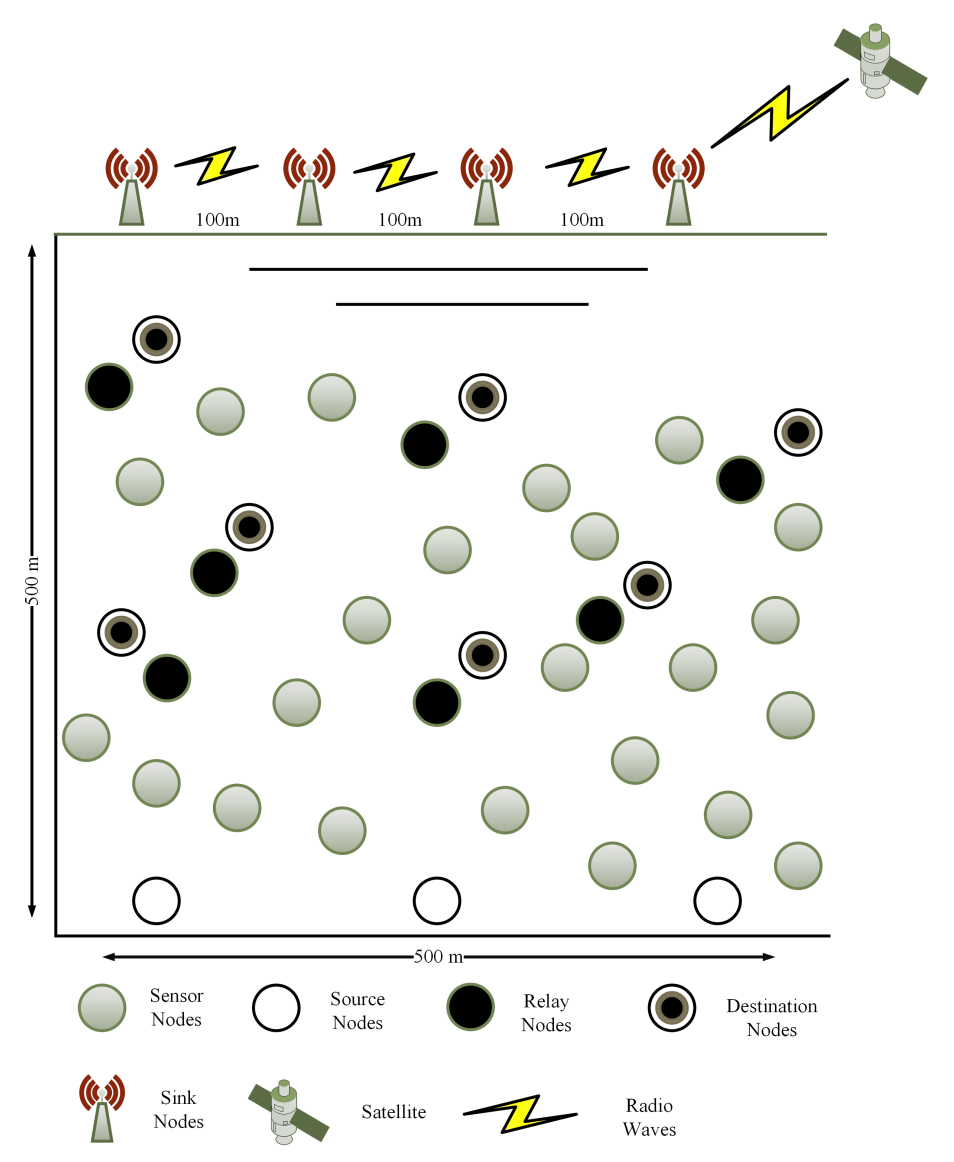

Figure 1. Network Architecture of the Proposed Protocols. 


\subsubsection{Information Acquisition}

The nodes in UWSNs initially do not have any information about the neighbor nodes which is required for routing. The residual energy, number of hops and BER information are needed in the proposed protocols. For the purpose of getting the information of each node, a hello test bag is transmitted by the final DNN towards the sensor nodes. The volume of the hello packet is considered 8 bytes, which is responsible to exchange all the required information among the sensor nodes [32]. After each 35 rounds, the hello packets are repeatedly exchanged among the nodes to keep the routing information updated. The unique ID of the sink differentiates the hello packet that it sends. A node directly receiving the packet from the final DNN inserts the value of the energy its has in its battery and hop count (which is unity for a node receiving the packet directly from the final DNN). The node then broadcasts the packet. Another node receiving this packet inserts its own residual energy and increments the number of hops (the new value becomes two) after the packet is received from the node with a single hop from the final DNN. This sequence is repeated unless nodes exchange residual energy and number of hops information. To calculate BER, a node sends a test bag to its neighbors. The test bag contains a specific number of bits. This pattern of bits is by default known to all nodes. Therefore, upon receiving the test bag, every node checks the number of bits changed (corrupted) in the test bag due to channel properties. Every node then informs the sender node about the number of corrupted bits in the test bag. The hello bag format is provided in Figure 2.

\begin{tabular}{|l|l|l|}
\hline Residual Energy & A Number of Hops & Bit Error Rate \\
\hline
\end{tabular}

Figure 2. Hello Packet Parameters.

\subsubsection{Destination Nodes Selection and Data Forwarding}

This part briefly explains the selection criteria of the DSNs and data forwarding mechanism. When the source nodes receive information about neighbors, the residual energy, number of hops and BER of each node is present in the field of the source nodes according to the manner discussed above. The node which has the maximum residual energy, fewest hops and the least bit error rate is chosen as the DSN. The selected DSN forwards the information bag to the next DSN via multi-hopping until the information packets reach to the final DNN. The next DSN selection criterion is the same as the first DSN selection. If the final DNN is in the range of the source node, then the information bag is directly transmitted to the final DNN. The proposed LFEER protocol checks the residual energy and number of hops of each node and selects such a DSN which is best in these parameters. As a result, energy consumed by the node reduces. Thus, the proposed LFEER algorithm can be practically implemented in scenarios where the communication for the longtime is needed, such as undersea monitoring. The forwarder selection is based on assigning a cost function or fitness function to each node based on residual energy $\left(R_{e}\right)$, number of hops $(n)$ and BER as

$$
f=R_{e} / n \times B E R .
$$

A node having the highest value of the function $f$ is chosen as a DSN.

\subsection{Cooperative Localization Free Energy Efficient Routing Protocol (Co-LFEER)}

This section explains the proposed Co-LFEER protocol in detail. The proposed Co-LFEER is the advanced version of the proposed LFEER protocol that uses cooperative routing. The fundamental steps of this protocol are briefly explained as below. 


\subsubsection{Selection of Destination and Relay Nodes and Data Forwarding}

The selection criteria of the DSN in the Co-LFEER protocol is the same as for the LFEER protocol. The protocol describes the DSN and RLNs having the same parameters for selection: residual energy, number of hops and bit error rate. The source node selects the only one RLN and the DSN to transmit the information bags in the direction of the final DNN. When the source nodes send the information packets in the broadcast nature, all nodes which are in the field of the source nodes receive the data packets. Then, only one DSN is chosen. Based on the function values, the RLNs are selected. A node is chosen as a RLN which has the second highest value of the cost function. The first highest function value is assigned to the DSN. The overall selection and data forwarding mechanism is provided in Algorithm 1.

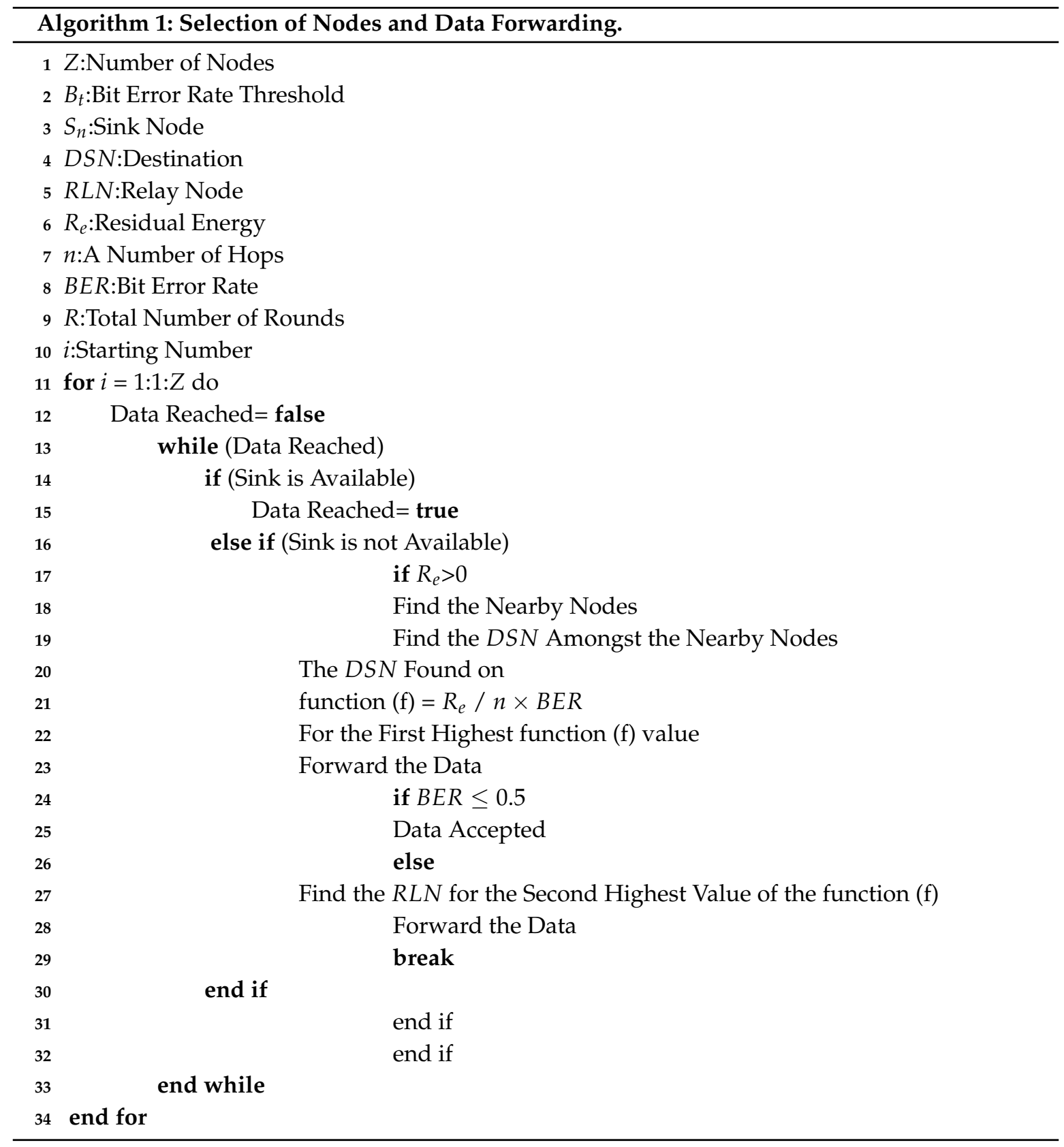


The information bags transmitting mechanism from the source to DSN, RLN and then to the final DNN as well as the direct transmitting path from the source to the final DNN is depicted in Figure 3.



Source Node
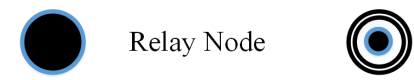

Destination Node

Figure 3. Data Transmission: (a) Cooperative Transmission; and (b) Direct Transmission.

\subsubsection{Cooperation of Destination and Single Relay Nodes}

In the proposed Co-LFEER protocol, cooperation of the DSN and the single RLN is involved in data packets forwarding. Thus, two copies of information bags are received at the DSN, i.e., one received directly via the source to DSN and the other via the RLN to DSN. Then, the two information bags are merged at the DSN through the MRC technique which converts these two data packets into one data packet. This is in the case when the final DNN is outside the field of the source node. If the final DNN is available inside the field of the source node, then the source node forwards the information bag directly to the final DNN. The BER threshold value is $\leq 0.5$. For every information packet, which is collected at the DSN, the protocol checks the BER threshold value. Whenever the information bag received at the DSN has the BER value $\leq 0.5$, the information bag is accepted and forwarded towards the next targeted node. If the information bag received has the BER $>0.5$, then the DSN requests to RLN to send the information bag which it has. The RLN performs AF cooperation at each information bag and then sends it to the DSN. The DSN once again checks the BER threshold value. If it is not satisfied, then the DSN drops the data bag. If the information bag received at the DSN satisfies the BER threshold value, then the DSN accepts it and forwards it in the direction of the next targeted node. If the final DNN is not present in the field of the source node, then through multi-hopping information bags are forwarded towards the final DNN.

The proposed Co-LFEER algorithm is efficient to minimize the channel effects on the information bags by selecting such a DSN and RLN which have minimum BER, highest residual energy and the fewest hops amongst all the nearby nodes. This helps to achieve the maximum information bags at the final DNN by consuming less energy. We can practically implement the Co-LFEER algorithm in battlefields and in defence monitoring for UWSNs, in which data loss is very critical. 


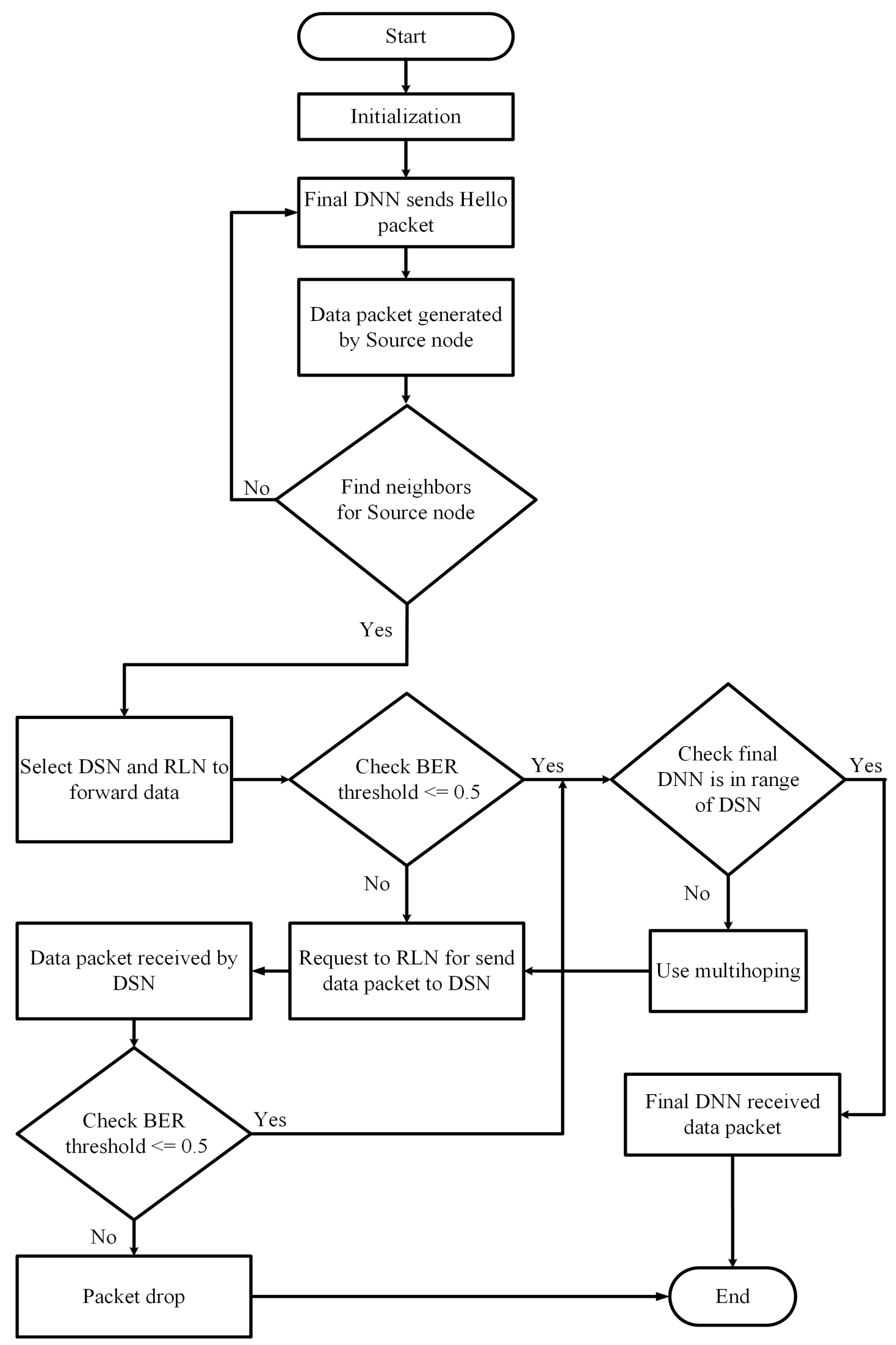

Figure 4. Flowchart of the LFEER and Co-LFEER. 
The flowchart of the LFEER and the Co-LFEER protocols is given in Figure 4. Firstly, network is initialized and for this purpose a hello packet is transmitted by the final DNN. With the help of hello packet, all the sensor nodes exchange their own information with each other. All the sensor nodes becomes familiar with each other regarding residual energy, number of hops and BER. Then, the information bags are generated by the source nodes. The goal of the framework is to send the maximum data packets toward the final DNN using the minimum energy. For this purpose, after the bags are generated, the source node has to find its nearby nodes. If found, it selects the DSN and RLN in its forwarding range based on the fitness function values. The data are forwarded in the direction of DSN. If the DSN and RLN nodes are not found, then source node sends a signal to the sink node. After receiving the data at the DSN, a BER checking process is set at each DSN. If the BER threshold is not satisfied by the packet received, then DSN requests to RLN to transmit its data. If BER threshold is satisfied, then the DSN checks if the final DNN is present in its range. If so, then data is forwarded to the final DNN. Otherwise, using multi-hopping, this process is repeated unless the final DNN is arrived. After receiving the data at the DSN through RLN, the DSN checks again the BER threshold on the packets which are received through RLN. If this time the BER is higher than the threshold, the DSN drops the packet. Otherwise, it looks for the final DNN if it is available in its range. Otherwise, multi-hopping continues.

The combining of two or more packets at the DSNs through MRC technique is given by [33].

$$
Y_{d}=\sum_{k=1}^{l} h_{k d}^{*} \times Y_{k d}
$$

where $l$ represents the signals input to the destination nodes, $h_{k d}^{*}$ stands for the conjugate channel gain and $Y_{k d}$ is the symbol received at the conjugated channel.

The amplifying factor to amplify the packets at the RLNs is given as [34].

$$
\beta \leq \sqrt{\frac{P}{\left|a_{s, r}\right|^{2} P+N_{o}}} .
$$

In the above equation, amplifier gain between the source and the forwarder nodes depend upon the fading coefficient $a_{s, r}$ where $P$ shows the transmitted power and $N_{o}$ shows the variance of noise.

\section{Simulation Results}

MATLAB simulates the proposed and counterpart protocols. The network contains 225 nodes which are deployed with irregular spacings. There are four final DNNs, which are static and kept at the water surface. The model initially assigns 10 Joules of energy to every node. The forwarding range of every node is considered $100 \mathrm{~m}$. In the proposed protocols, the depth threshold for the nodes are fixed. A total of 11,200 information bags are transmitted in the direction of final DNN. Some of the packets are dropped due to high BER and many other channel effects, and many of the packets are successfully received at the final DNN. One data bag contains 1600 bits. The MAC layer makes the data link layer (DLL) in the OSI model. The protocol designed for the DLL is MAC. The MAC protocol explains the transmission mechanism of the data packets in a channel [35]. The sensor nodes can move freely without any restriction due to water flow. The speed of sensor nodes due to water currents are approximately up-to $5 \mathrm{~m} / \mathrm{s}$ [36]. The comparison of the proposed protocols with each other and the Co-DBR protocol for UWSNs is shown in simulation results. The proposed protocols are compared with the Co-DBR because the Co-LFEER and the Co-DBR use cooperative routing, which counteracts channel worst conditions and LFEER also computes links affected by channels. The simulation results indicate that the proposed LFEER algorithm is good in residual energy, alive nodes, dead nodes and delay than the Co-LFEER and the Co-DBR protocols. The Co-LFEER algorithm is better in terms of 
residual energy, alive nodes, dead nodes and PDR than the Co-DBR protocol. The overall performance of the Co-LFEER is better than the Co-DBR protocol. One round is the time instant responsible for advancement of one or more packets to water surface. The basic information of each protocol LFEER, Co-LFEER and Co-DBR is presented in Table 3.

Table 3. Protocols Information.

\begin{tabular}{lllll}
\hline Protocol & Cooperation & Sink Nodes & Depth Threshold & Nodes Selection Parameters \\
\hline LFEER & $\begin{array}{l}\text { Not } \\
\text { involved. }\end{array}$ & $\begin{array}{l}\text { Placed at the top of the } \\
\text { water and static. }\end{array}$ & Fixed. & $\begin{array}{l}\text { Residual energy, A Number } \\
\text { of hops, Bit error rate. }\end{array}$ \\
\hline \multirow{2}{*}{ Co-LFEER } & $\begin{array}{l}\text { Involved } \\
\text { with one } \\
\text { relay node. }\end{array}$ & $\begin{array}{l}\text { Placed at the top of the } \\
\text { water surface and static. }\end{array}$ & Fixed. & $\begin{array}{l}\text { Residual energy, A Number } \\
\text { of hops, Bit error rate. }\end{array}$ \\
\hline \multirow{2}{*}{ Co-DBR } & $\begin{array}{l}\text { Involved } \\
\text { with two } \\
\text { relay nodes. }\end{array}$ & $\begin{array}{l}\text { Static and placed at } \\
\text { upper surface of the } \\
\text { water. }\end{array}$ & Fixed. \\
\hline
\end{tabular}

The residual energy of the network is presented in Figure 5. The proposed LFEER protocol has the highest residual energy. This is because the information bags are forwarded to the final DNN through one path and neighbor nodes do not cooperate with each other, which consumes extra energy. In the proposed Co-LFEER protocol, residual energy is less than the LFEER protocol due to cooperation technique. However, in the Co-LFEER protocol, the residual energy is higher than the Co-DBR because of the data forwarding with a single relay node in the latter. Although, the residual energy of the proposed LFEER and the Co-LFEER protocols is higher than the Co-DBR up to 600 rounds, from 600 to 900 rounds, the residual energy of all protocols becomes the same because fewer nodes are left in the network that do not participate mainly because majority of the nodes have died. As a result, nodes do not mainly participate in data routing so their energy consumption almost becomes the same.

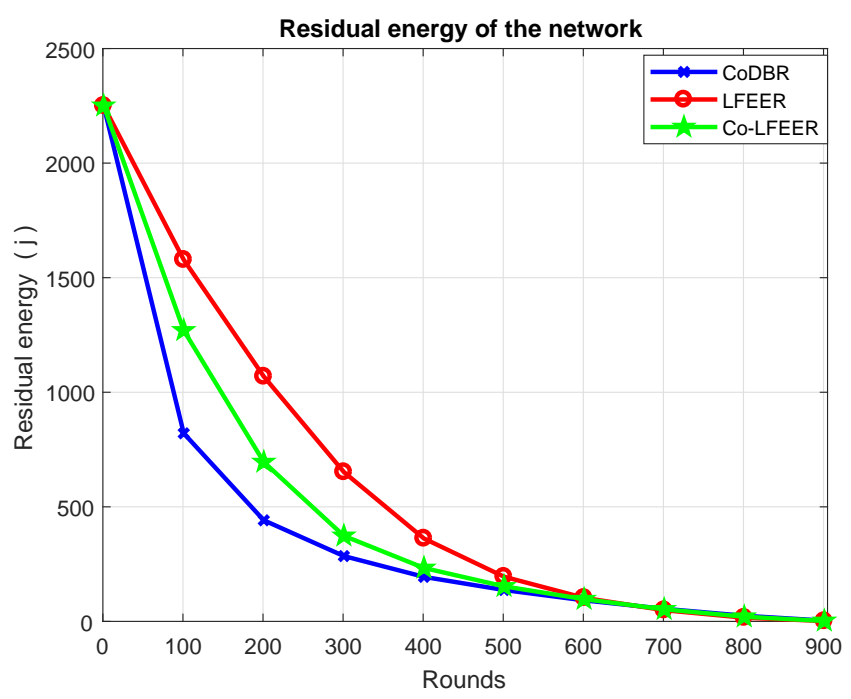

Figure 5. Residual energy.

Having more alive nodes guarantees the maximum forwarding of information packets. As a result, it increases the data packets transmission rate towards the sink nodes. Figure 6 shows the proposed LFEER protocol has the maximum alive nodes. This is due to the reason that in the proposed LFEER protocol only one DSN transmits the information bags toward the final DNN. Thus, the least energy is consumed and there are maximum alive alive nodes. The proposed Co-LFEER protocol has more alive 
nodes than the Co-DBR protocol, because in Co-LFEER protocol only one RLN and the DSN contribute to transmit the information bags toward the targeted nodes. In the Co-DBR protocol, two forwarder nodes and the DSN transmit the information bag towards the final DNN, which consumes more energy and thus results in fewer alive nodes.

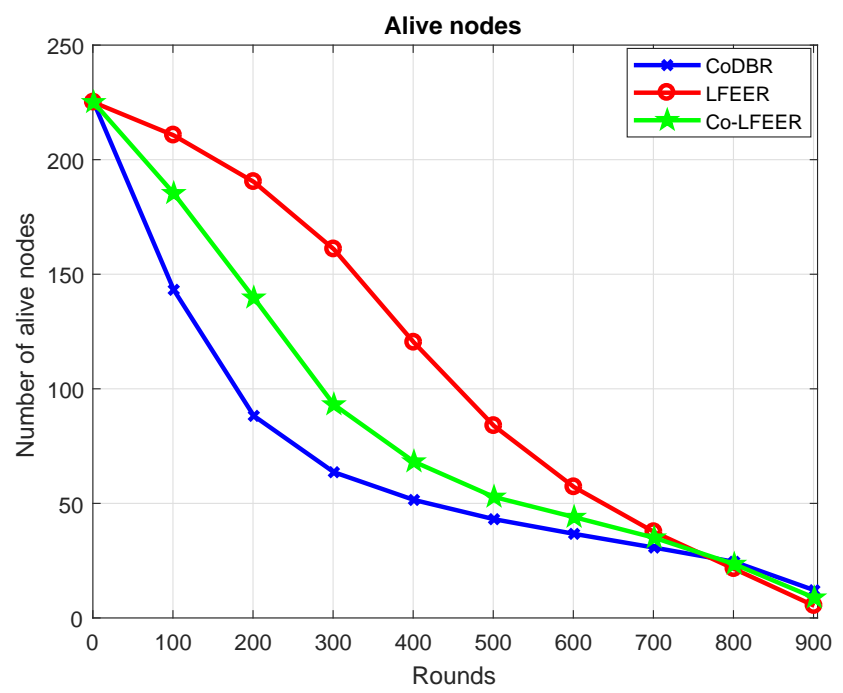

Figure 6. Alive nodes.

The numbers of dead node is lower in count in the proposed LFEER and Co-LFEER protocols than Co-DBR, as shown in Figure 7. The LFEER protocol has the least count of dead nodes than the Co-DBR and the Co-LFEER due to the absence of cooperation and by selecting the only one DSN in the information bags transmission towards the final DNN. The Co-LFEER has cooperation by considering a single RLN and the Co-DBR involves cooperation with the two relay nodes in data bags transmission. Thus, the Co-LFEER protocol consumes less energy and has fewer dead nodes than the Co-DBR. The number of dead nodes at the end of 500 rounds identifies that the death rate of the nodes in the Co-DBR protocol is the maximum. After 500 rounds, in Co-DBR there are 175 dead node, in the LFEER there are 145 dead nodes and in the Co-LFEER there are 165 dead nodes.

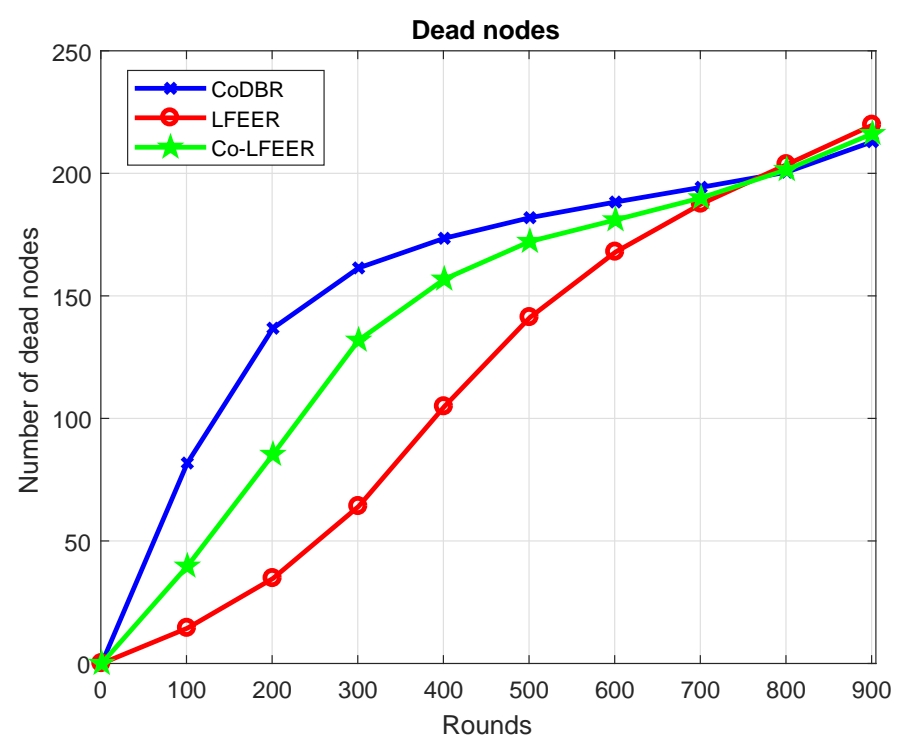

Figure 7. Dead nodes. 
Figure 8 represents the comparative results of packets delivery ratio. In the proposed LFEER protocol, no cooperation is included, which minimizes the PDR as compared to the Co-LFEER and the Co-DBR protocols. The proposed Co-LFEER protocol has the maximum PDR because, in the Co-LFEER protocol, cooperation involves RLN with the minimum bit error rates. By doing this, packet drop and path loss effect decrease and correspondingly packets delivery ratio increases. On the other hand, the Co-DBR protocol has not involved BER in selection criteria for the destination and relay nodes which degrades the PDR. Figure 8 shows that, from round 0 to round 150, the PDR of the proposed Co-LFEER and the Co-DBR protocols is the same because, initially, every protocol uses its best nodes in data advancement. Later, death of such nodes and intelligent selection of nodes to mitigate channel effects in the Co-LFEER makes its PDR the highest.

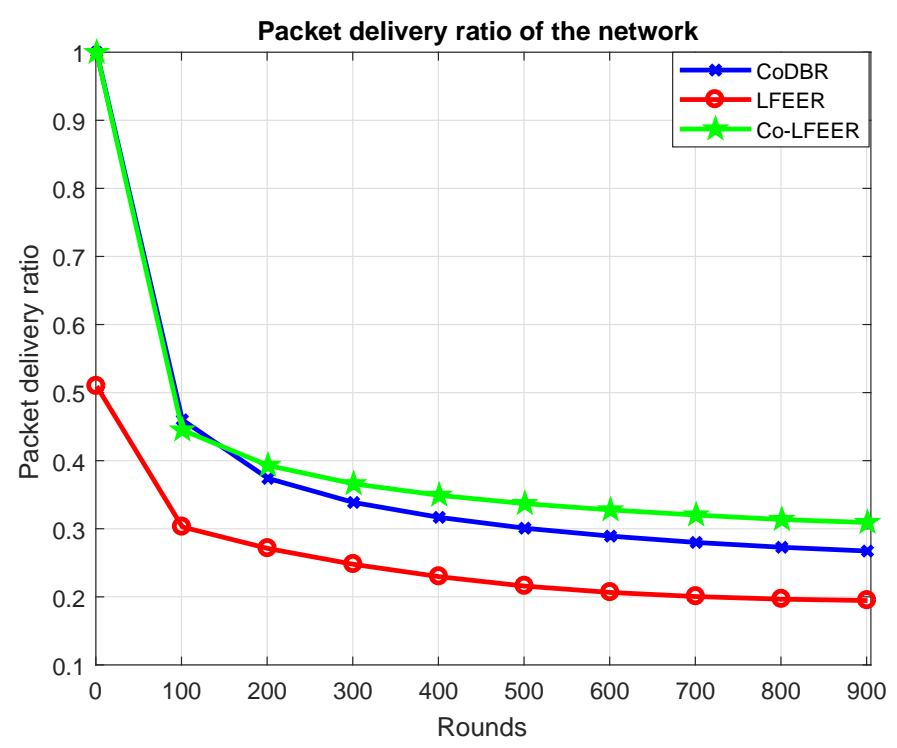

Figure 8. Total packets delivery ratio.

The delay is exhibited in Figure 9. The proposed LFEER protocol has the smallest delay due to the absence of cooperation in data packets transmission. From round 0 to round 180, the proposed Co-LFEER protocol has less delay than the Co-DBR as nodes providing low delay are alive in the latter. Such nodes die later, after 180 rounds, making delay in Co-LFEER higher.

In summary, the LFEER protocol provides efficient consumption of power of nodes and considers channel impairments in the form of fitness criterion of the nodes that route packets. This feature is lacking in the Co-DBR and other protocols described above. Rather, channel impairments are dealt with at the cost of high energy consumption in these protocols. On the other hand, the Co-LFEER protocol combines channel impairments with cooperative routing and is independent of the localization of nodes. The Co-DBR blindly selects nodes during cooperation without considering channel impairments. In addition, other related protocols described above either do not consider channel impairments or require localization of nodes. These feature compromise throughput, which Co-LFEER avoids. 


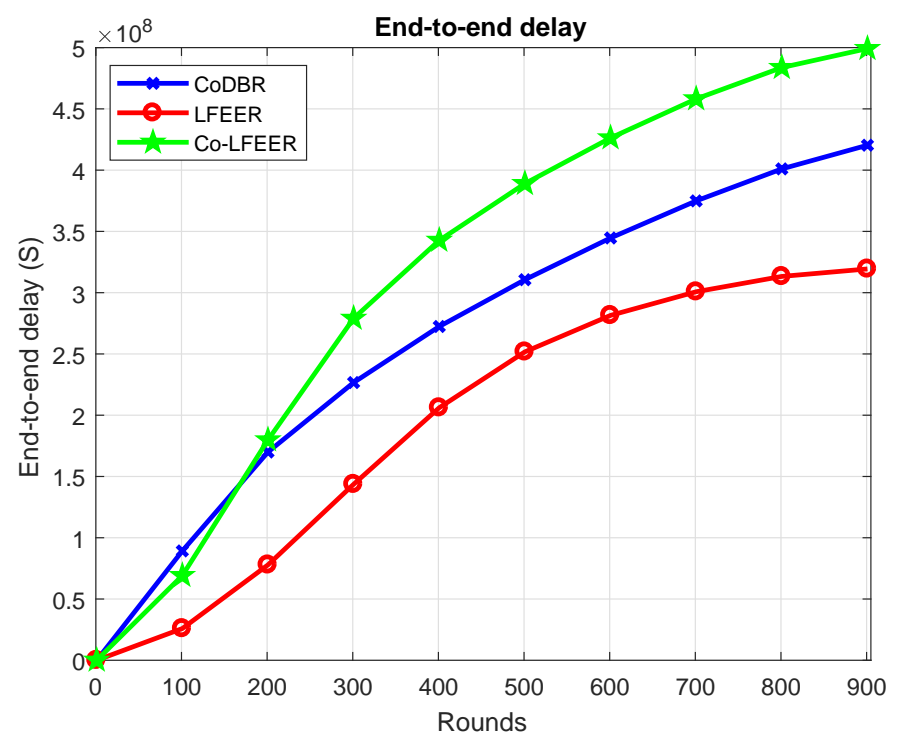

Figure 9. Network Delay.

\section{Conclusions and Future Task}

This paper proposes two routing protocols: localization free energy efficient routing protocol (LFEER) and localization free energy efficient cooperative routing protocol (Co-LFEER) for UWSNs. An energy controlling mechanism is defined for the selection of the destination in the proposed LFEER protocol, in which the destination choice is made based on a function value using residual energy, number of hops and bit error rate. The node that has the greatest function value is selected as a destination. In the Co-LFEER protocol, only one forwarder node is chosen to cooperate with the destination. The same parameters (residual energy, number of hops, and BER) are used for the selection of the forwarder node. The node having the second highest value of the function acts as a relay, as the first highest value is assigned to the destination. Simulation results indicate that the proposed LFEER and Co-LFEER maximize the residual energy of the network and have more alive nodes than the Co-DBR protocol. In addition, PDR of the network is improved. The LFEER can be practically implemented where longtime communication is needed. In future, the delay of the proposed Co-LFEER protocol can be minimized to make it flexible to many applications.

Author Contributions: A.K. proposed the main idea. S.S. implemented the idea and wrote the manuscript. I.A. and K.-M.K. streamlined the flow of the manuscript. H.M. responded to the comments of the reviewers.

Funding: This research was supported by Basic Science Research Program through the National Research Foundation of Korea (NRF) funded by the Ministry of Education (2017030223).

Conflicts of Interest: The authors declare no conflict of interest regrading the publication of this manuscript.

\section{Abbreviations}

Abbreviation used in the article:

DNN (s) Destination (s)

RLN (s) Relay node (s)

DSN (s) Destination node (s)

PDR Packet delivery ratio

BER Bit error rate

AF Amplify and forward

DF Decode and forward 
RSSI Received signal strength indicator

DLL Data link layer

OSI Open system interconnection

MAC Media access control

GPS Global position system

SNR Signal to noise ratio

MRC Maximal ratio combine

\section{References}

1. Khasawneh, A.; Latiff, M.S.B.A.; Kaiwartya, O.; Chizari, H. Next forwarding node selection in underwater wireless sensor networks (UWSNs): Techniques and challenges. Information 2016, 8, 3. [CrossRef]

2. Wahid, A.; Lee, S.; Kim, D. A reliable and energy efficient routing protocol for underwater wireless sensor networks. Int. J. Commun. Syst. 2014, 27, 2048-2062. [CrossRef]

3. Zhou, Z.; Yao, B.; Xing, R.; Shu, L.; Bu, S. E-CARP: An energy efficient routing protocol for UWSNs in the internet of underwater things. IEEE Sens. J. 2016, 16, 4072-4082. [CrossRef]

4. Basagni, S.; Petrioli, C.; Petroccia, R.; Spaccini, D. CARP: A channel-aware routing protocol for underwater acoustic wireless networks. Ad Hoc Netw. 2015, 34, 92-104. [CrossRef]

5. Khan, A.; Ali, I.; Rahman, A.U.; Imran, M.; Mahmood, H. Co-EEORS: Cooperative Energy Efficient Optimal Relay Selection Protocol for Underwater Wireless Sensor Networks. IEEE Access 2018, 28777-28789. [CrossRef]

6. Khasawneh, A.; Latiff, M.S.B.A.; Chizari, H.; Tariq, M.; Bamatraf, A. PRESSURE BASED ROUTING PROTOCOL for UNDERWATER WIRELESS SENSOR NETWORKS: A SURVEY. KSII. Trans. Int. Inf. Syst. 2015, 9. [CrossRef]

7. Jouhari, M.; Ibrahimi, K.; Benattou, M.; Kobbane, A. New greedy forwarding strategy for UWSNs geographic routing protocols. In Proceedings of the 2016 International Wireless Communications and Mobile Computing Conference (IWCMC), Paphos, Cyprus, 5-9 September 2016; pp. 388-393.

8. Nasir, H.; Javaid, N.; Murtaza, M.; Manzoor, S.; Khan, Z.A.; Qasim, U.; Sher, M. ACE: Adaptive cooperation in EEDBR for underwater wireless sensor networks. In Proceedings of the 2014 Ninth International Conference on Broadband and Wireless Computing, Communication and Applications, Guangdong, China, 8-10 November 2014; pp. 8-14.

9. Shah, P.M.; Ullah, I.; Khan, T.; Hussain, M.S.; Khan, Z.A.; Qasim, U.; Javaid, N. MobiSink: Cooperative routing protocol for underwater sensor networks with sink mobility. In Proceedings of the 2016 IEEE 30th International Conference on Advanced Information Networking and Applications (AINA), Crans-Montana, Switzerland, 23-25 March 2016; pp. 189-197.

10. Javaid, N.; Jafri, M.R.; Khan, Z.A.; Qasim, U.; Alghamdi, T.A.; Ali, M. Iamctd: Improved adaptive mobility of courier nodes in threshold-optimized dbr protocol for underwater wireless sensor networks. Int. J. Distrib. Sens. Netw. 2014, 10, 213012. [CrossRef]

11. Maqsood, H.; Javaid, N.; Zain-ul-Abidin, M.; Ejaz, M.; Shakeel, U. Energy balanced interference aware energy efficient depth base routing protocol for UWSNs. In Proceedings of the 2015 10th International Conference on Broadband and Wireless Computing, Communication and Applications (BWCCA), Krakow, Poland, 4-6 November 2015; pp. 13-19.

12. Ahmed, S.; Javaid, N.; Ahmad, A.; Ahmed, I.; Durrani, M.Y.; Ali, A.; Haider, S.B.; Ilahi, M. SPARCO: Stochastic performance analysis with reliability and cooperation for underwater wireless sensor networks. J. Sens. 2016. [CrossRef]

13. Ahmad, A.; Ahmed, S.; Imran, M.; Alam, M.; Niaz, I.A.; Javaid, N. On energy efficiency in underwater wireless sensor networks with cooperative routing. Ann. Telecommun. 2017, 72, 173-188. [CrossRef]

14. Han, G.; Liu, L.; Jiang, J.; Shu, L.; Rodrigues, J.J. A collaborative secure localization algorithm based on trust model in underwater wireless sensor networks. Sensors 2016, 16, 229. [CrossRef] [PubMed]

15. Javaid, N.; Maqsood, H.; Wadood, A.; Niaz, I.A.; Almogren, A.; Alamri, A.; Ilahi, M. A localization based cooperative routing protocol for underwater wireless sensor networks. Mob. Inf. Syst. 2017. [CrossRef]

16. Javaid, N.; Hussain, S.; Ahmad, A.; Imran, M.; Khan, A.; Guizani, M. Region based cooperative routing in underwater wireless sensor networks. J. Netw. Comput. Appl. 2017, 92, 31-41. [CrossRef] 
17. Hao, K.; Shen, H.; Liu, Y.; Wang, B.; Du, X. Integrating Localization and Energy-Awareness: A Novel Geographic Routing Protocol for Underwater Wireless Sensor Networks. Mob. Netw. Appl. 2018, 1-9. [CrossRef]

18. Ali, M.T.; Rahim, S.S.; Jan, M.A.; Ishtiaq, A.; Ahmed, S.; Ahmad, M.; Khan, M.; Khan, M.A. Dist-Coop: Distributed Cooperative Transmission in UWSNs using Optimization Congestion Control and Opportunistic Routing. Int. J. Adv. Comput. Sci. Appl. 2018, 9, 356-368. [CrossRef]

19. Hafeez, T.; Javaid, N.; Shakeel, U.; Hussain, S.; Maqsood, H. An Energy Efficient Adaptive Cooperative Routing Protocol for Underwater WSNs. In Proceedings of the 2015 10th International Conference on Broadband and Wireless Computing, Communication and Applications (BWCCA), Krakow, Poland, 4-6 November 2015; pp. 304-310.

20. Shah, M.; Javaid, N.; Imran, M.; Guizani, M.; Khan, Z.A.; Qasim, U. Interference aware inverse EEDBR protocol for underwater WSNs. In Proceedings of the 2015 International Wireless Communications and Mobile Computing Conference (IWCMC), Dubrovnik, Croatia, 24-28 August 2015; pp. 739-744.

21. Rahman, M.A.; Lee, Y.; Koo, I. EECOR: An energy-efficient cooperative opportunistic routing protocol for Underwater acoustic sensor networks. IEEE Access 2017, 5, 14119-14132. [CrossRef]

22. Umar, A.; Akbar, M.; Iqbal, Z.; Khan, Z.A.; Qasim, U.; Javaid, N. Cooperative partner nodes selection criteria for cooperative routing in underwater WSNs. In Proceedings of the 20155 th National Symposium on Information Technology: Towards New Smart World (NSITNSW), Riyadh, Saudi Arabia, 17-19 February 2015; pp. 1-7.

23. Pervaiz, K.; Wahid, A.; Sajid, M.; Khizar, M.; Khan, Z.A.; Qasim, U.; Javaid, N. DEAC: Depth and energy aware cooperative routing protocol for underwater wireless sensor networks. In Proceedings of the 2016 10th International Conference on Complex, Intelligent, and Software Intensive Systems (CISIS), Fukuoka, Japan, 6-8 July 2016; pp. 150-158.

24. Khan, A.; Ejaz, M.; Javaid, N.; Azeemi, M.Q.; Qasim, U.; Khan, Z.A. EEORS: Energy Efficient Optimal Relay Selection Protocol for Underwater WSNs. In Proceedings of the 2016 19th International Conference on Network-Based Information Systems (NBiS), Ostrava, Czech Republic, 7-9 September 2016; pp. 239-245.

25. Umar, A.; Javaid, N.; Ahmad, A.; Khan, Z.A.; Qasim, U.; Alrajeh, N.; Hayat, A. DEADS: depth and energy aware dominating set based algorithm for cooperative routing along with sink mobility in underwater WSNs. Sensors 2015, 15, 14458-14486. [CrossRef] [PubMed]

26. Tsiropoulou, E.E.; Paruchuri, S.T.; Baras, J.S. Interest, energy and physical-aware coalition formation and resource allocation in smart IoT applications. In Proceedings of the 2017 51st Annual Conference on Information Sciences and Systems (CISS), Baltimore, MD, USA, 22-24 March 2017; pp. 1-6.

27. Lin, C.R.; Gerla, M. Adaptive clustering for mobile wireless networks. IEEE J. Sel. Areas Commun. 1997, 15, 1265-1275. [CrossRef]

28. Tsiropoulou, E.E.; Mitsis, G.; Papavassiliou, S. Interest-aware energy collection and resource management in machine to machine communications. Ad Hoc Netw. 2018, 68, 48-57. [CrossRef]

29. Gerla, M.; Kwon, T.J.; Pei, G. On-demand routing in large ad hoc wireless networks with passive clustering. In Proceedings of the 2000 IEEE Wireless Communications and Networking Conference, Chicago, IL, USA, 23-28 September 2000; Volume 1, pp. 100-105.

30. Tsiropoulou, E.E.; Koukas, K.; Papavassiliou, S. A socio-physical mobility-aware coalition formation in public safety networks. EAI Endorsed Trans. 2018, 3, 1-9. [CrossRef]

31. Gerla, M.; Tsai, J.T.C. Multicluster, mobile, multimedia radio network. Wirel. Netw. 1995, 1, $255-265$. [CrossRef]

32. Majid, A.; Azam, I.; Waheed, A.; Zain-ul-Abidin, M.; Hafeez, T.; Khan, Z.A.; Qasim, U.; Javaid, N. An energy efficient and balanced energy consumption cluster based routing protocol for underwater wireless sensor networks. In Proceedings of the 2016 IEEE 30th International Conference on Advanced Information Networking and Applications (AINA), Crans-Montana, Switzerland, 23-25 March 2016; pp. 324-333.

33. El-Darymli, K. Amplify-and-forward cooperative relaying for a linear wireless sensor network. In Proceedings of the 2010 IEEE International Conference on Systems, Man and Cybernetics, Istanbul, Turkey, 10-13 October 2010; pp. 106-112.

34. Laneman, J.N.; Tse, D.N.; Wornell, G.W. Cooperative diversity in wireless networks: Efficient protocols and outage behavior. IEEE Trans. Inf. Theory 2004, 50, 3062-3080. [CrossRef] 
35. Al Salti, F.; Alzeidi, N.; Arafeh, B.R. EMGGR: An energy-efficient multipath grid-based geographic routing protocol for underwater wireless sensor networks. Wirel. Netw 2017, 23, 1301-1314. [CrossRef]

36. Li, M.; Du, X.; Huang, K.; Hou, S.; Liu, X. A routing protocol based on received signal strength for underwater wireless sensor networks (UWSNs). Information 2017, 8, 153. [CrossRef]

(C) 2018 by the authors. Licensee MDPI, Basel, Switzerland. This article is an open access article distributed under the terms and conditions of the Creative Commons Attribution (CC BY) license (http:/ / creativecommons.org/licenses/by/4.0/). 